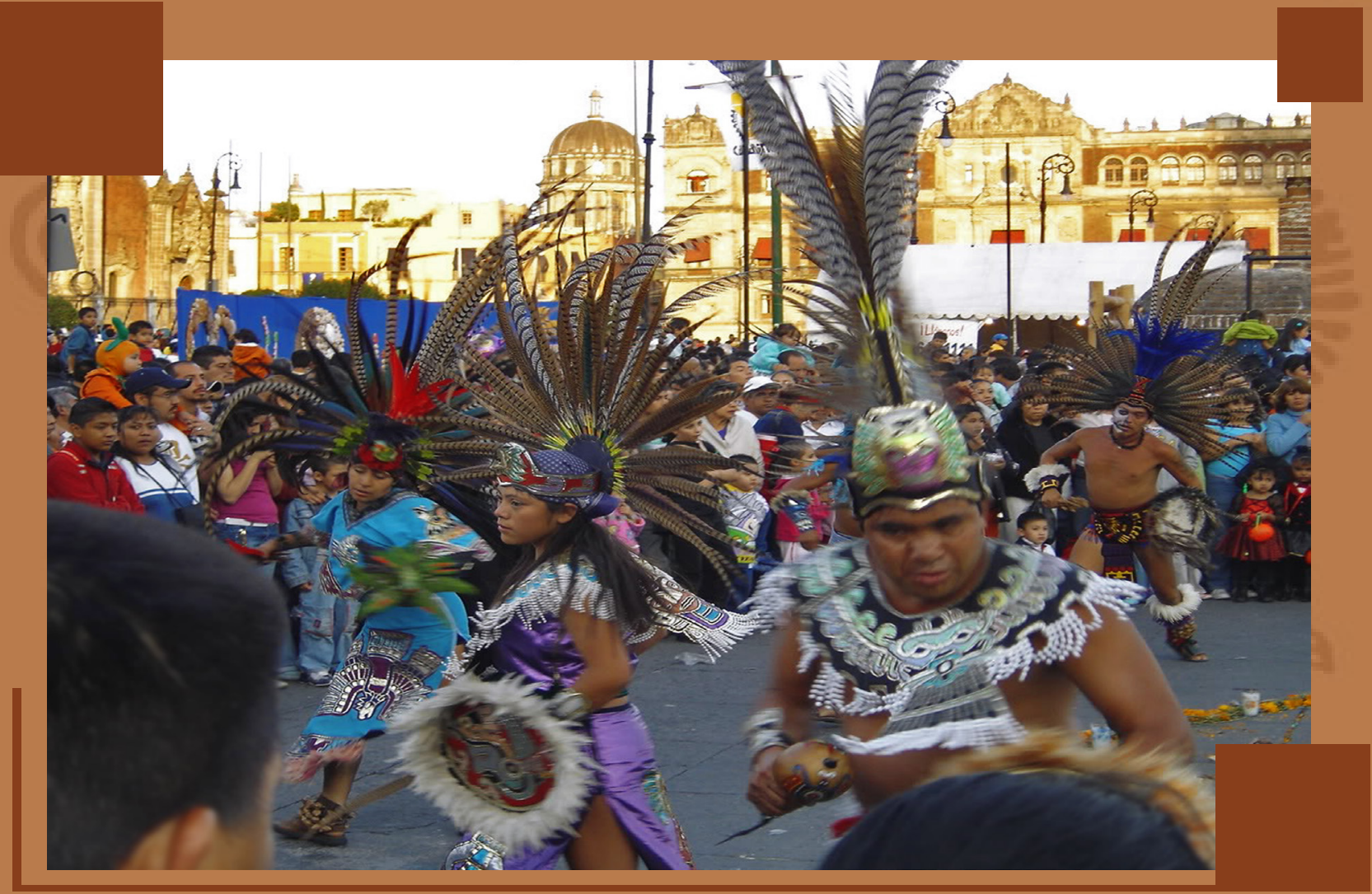

\title{
Evolución del estado \\ de Nicaragua, desde la perspectiva intercultural
}

Pueblo, Cultura e Identidad 


\section{Evolución del Estado de Nicaragua desde la perspectiva intercultural}

\section{Evolution of the State of Nicaragua, from the Intercultural Perspective}

Rigoberto Mairena Ruiz

Abogado, Investigador independiente

ID Orcid: https://orcid.org/0000-0002-6579-9672

rigobertomai_2004@yahoo.es

Recibido: 28-10-2019

Aceptado: 20-11-2019

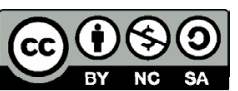

Copyright $\odot 2020$ UNAN-Managua Todos los Derechos Reservados.

\section{Resumen}

El Estado de Nicaragua, surgió como un instrumento de las élites de la cultura dominante ( castellana), para someter a las otras culturas que existían a la llegada de los europeos y que lograron sobrevivir a la colonización castellana e inglesa. Después de la mal llamada independencia de Centroamérica, las élites criollas asumieron la misión de darle continuidad y concluir el proyecto de colonización iniciado en el siglo XVI. Con éste propósito hicieron todo para tomar el poder y diseñar un modelo de Estado capaz de asegurar sus intereses. Durante siglo y medio, ese instrumento político de dominación cultural, funcionó efectivamente en todos sus componentes, pero fue la educación pública el principal vehículo de sometimiento cultural, especialmente a partir de finales del siglo XIX. No obstante, a partir del triunfo dela Revolución en 1979, se inició un verdadero proceso de independencia, que abarcó todos los ámbitos de la sociedad y fue la cultura uno de los pilares fundamentales de la creación de una nueva sociedad. En el transcurso de estas cuatro décadas, se ha venido desarrollando un proceso de diálogo intercultural, a partir del cual, los pueblos indígenas y afrodescendientes, paulatinamente han logrado avances muy trascendentales, para el desmontaje del sistema colonial republicano. Este proceso de descolonización alcanza su cúspide, con las Reformas Constitucionales febrero 2014, en las cuales se incluyen disposiciones que permiten ubicar a Nicaragua, como un Estado Pluricultural. En éste trabajo, pretendemos explicar el desarrollo de este proceso de descolonización, destacando el protagonismo de los Pueblos Indígenas y Afrodescendientes en los diferentes mementos históricos.

Palabras claves: Interculturalidad, Identidad, Estado, Cultura, Pueblos Originarios.

\section{Abstract}

The State of Nicaragua emerged as an instrument of the elites of the dominant (Castilian) culture, to subdue the other cultures that existed at the arrival of the Europeans and that managed to survive the Castilian and English colonization. After the so-called independence of Central America, the Creole elites assumed the mission of giving it continuity and concluding the colonization project begun in the 16th century. With this purpose, they did everything to take power and design a state model capable of assuring their interests. For a century and a half, this political instrument of cultural domination worked effectively in all its components, but public education was the main vehicle of cultural submission, especially from the end of the 19th century. However, after the triumph of the Revolution in 1979, a true process of independence began, which covered all areas of society and culture was one of the fundamental pillars of the creation of a new society. Over the course of these four decades, a process of intercultural dialogue has been developing, from which indigenous and Afro-descendant peoples have gradually made very significant progress in dismantling the republican colonial system. This decolonization process reaches its peak, with the Constitutional Reforms in February 2014, which include provisions that allow Nicaragua to be located as a Pluricultural State. In this work, we try to explain the development of this decolonization process, highlighting the role of Indigenous and Afro-descendant Peoples in the different historical moments. 
Keywords: Interculturality, Identity, State, Culture, Original Peoples.

Portada: Festividad popular en el Zocalo, CDMX, México.

Foto: Yalpri Moncada, 2014
La intención de sometimiento, fue el motivo de la constante confrontación entre la cultura ibérica y todas las demás culturas existentes en Nicaragua.

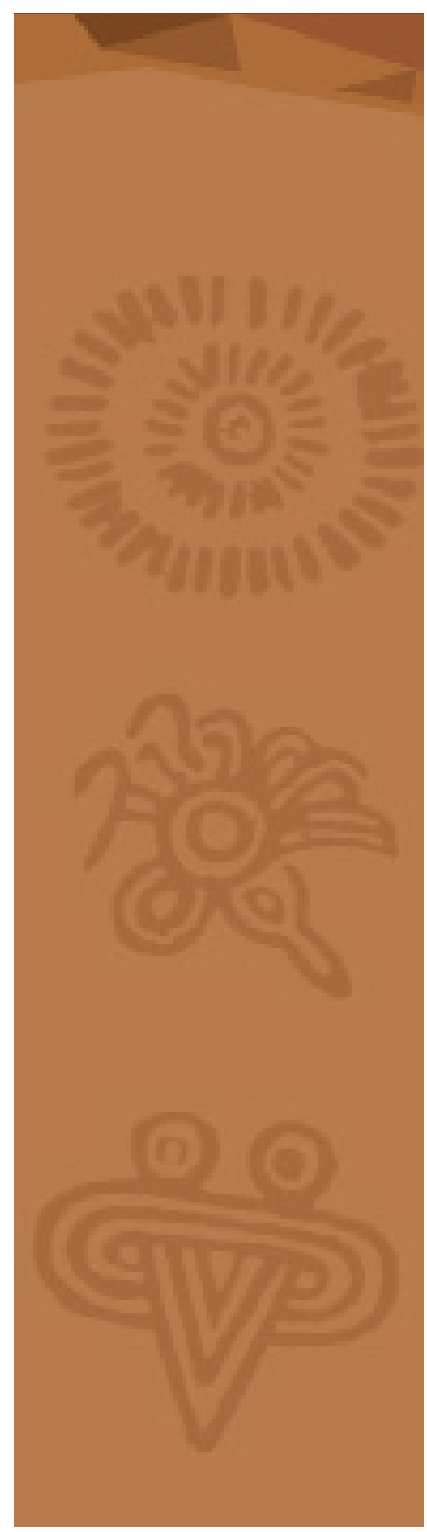

\section{Introducción}

El histórico diálogo entre el Cacique Nicarao y Gil González de Ávila, ocurrido en la segunda semana del mes de abril de 1522, inicia la relación entre dos bloques culturales que, a lo largo de cinco siglos, habrán de enfrentarse continuamente. Aunque en el encuentro se manifestaron dos culturas diferentes, no sólo en los aspectos rituales, sino en lo social y filosófico. No podría decirse que este encuentro inicia el diálogo intercultural; pues el propósito no era establecer una comunicación entre iguales y alcanzar un acuerdo basado en la paridad y respeto mutuo, sino en la intención preconcebida de someter el uno al otro. Esta es la diferencia entre el diálogo cultural y el diálogo intercultural.

La intención de sometimiento, fue el motivo de la constante confrontación entre la cultura ibérica y todas las demás culturas existentes en Nicaragua. Marcan el desarrollo de la Historia Nacional, durante los cinco siglos posteriores al encuentro entre nuestro Cacique Nicarao y el Capitán español. Este conflicto, aunque inadvertido, tiene un trasfondo étnico-cultural, en el cual es visible el protagonismo de los Pueblos Originarios y afrodescendientes, por la restitución de sus derechos históricos.

Le tesis de este trabajo, es que en Nicaragua los Pueblos Originarios y Afrodescendientes, han logrado mediante su protagonismo político, la creación de un Estado Pluricultural, que representa la diversidad cultural del país y establece las bases para el desarrollo de la interculturalidad.

Es necesario advertir, que este trabajo analiza la evolución de la interculturalidad en Nicaragua, desde la perspectiva política y jurídica, no antropológica, aunque bien se esbozan análisis ensamblados en esta corriente del pensamiento. Trataremos de abordar, como a lo largo de la historia las relaciones entre la cultura hispánica, que el Estado asumió como cultura oficial, y las culturas originarias y afrodescendientes, se han desarrollado en un proceso de confrontación y violencia, que no cesará sino hasta alcanzar una relación de poder; en la cual todas las culturas tengan un espacio para su desarrollo y todas estén representadas en un Estado, que no sea instrumento de sometimiento de una contra la otra. Afortunadamente este momento histórico para el país, inició desde hace cuatro décadas y se ha consolidado con las Reformas a la Constitución Política, aprobadas en febrero del año 2014.

\section{Antecedentes Históricos}

La historia de Nicaragua como Estado independiente, ha transcurrido en la búsqueda constante de su identidad propia. Con éste propósito, se han orientado los principales acontecimientos políticos desde la firma de la llamada Acta de Independencia el 15 de septiembre de 1,821 hasta nuestros días. 
En los movimientos sociales y políticos que han generado cambios a diferentes niveles, han estado siempre los pueblos originarios y afrodescendientes, como protagonistas directos. Así podemos afirmar con las insurrecciones indígenas de 1811-1812 en Granada, Rivas, Masaya y León, dirigidas por el afrodescendiente Cleto Ordoñez y el Indígena Ramón Pacheco, quienes además dirigieron la insurrección post independencia de 1822-1824 llamada la Gran Guerra, que fue la que permitió la sustitución definitiva de los funcionarios fieles a la Corona española. En la primera de estas insurrecciones, destaca la figura del Sacerdote indígena Fray Tomás Ruiz. ${ }^{1}$ Cabe destacar que producto de esta participación beligerante de los indígenas en las luchas políticas, lograron obtener un Diputado Constitucionalista que los representara en la Primera Asamblea Nacional Constituyente, conformada en 1824 y que redactó la Primera Constitución Política de Nicaragua, promulgada el 22 de abril de 1826.

El protagonismo de los pueblos indígenas y afrodescendiente, se destaca en todos los movimientos políticos, acontecidos en el período republicano. En la Guerra Nacional en la que destacan los indios flecheros de Matagalpa. La Guerra Antimperialista del General Sandino, con su Ejército Defensor de la Soberanía Nacional integrado por indígenas y afrodescendientes. La lucha contra la dictadura somocista, donde destacan las bases guerrilleras indígenas en el norte y las insurrecciones de Sutiaba y Monimbó. En la década de los 80, los pueblos indígenas y afrodescendientes de la Costa Caribe, alzaron la bandera étnica, en la cual se reclamaba al Estado de Nicaragua, el respeto a su autonomía, movimiento que culminó con un diálogo intercultural, que produjo la Ley de Autonomía de la Costa Caribe y con ella a la transformación del Estado de Nicaragua.

El Modelo de Estado que actualmente funciona en Nicaragua, se ha venido configurando paulatinamente en cada momento histórico, como producto de estos movimientos sociales y políticos, que han provocado los cambios; por lo cual se puede afirmar que los pueblos originarios y afrodescendientes, son los forjadores del mismo.

La evolución de las relaciones culturales hacia la interculturalidad, se analizan en un proceso histórico ascendente, en el cual se identifican tres períodos que trascurren dentro de la etapa colonial y republicana. La etapa colonial propiamente dicha, la etapa republicana desde 1826 hasta 1979, y de 1980 hasta 2014.

Con el triunfo de la Revolución Popular Sandinista en 1979, se inicia un proceso de diálogo intercultural con los pueblos originarios y afrodescendientes, inaugurando un proceso interactivo de transformaciones políticas y jurídicas, para construir un Modelo de Estado incluyente que represente la diversidad cultural existente en Nicaragua.

En el ámbito jurídico, se ha creado un andamiaje legal que permite afirmar que actualmente el Estado de Nicaragua, ha cumplido sus compromisos ante la Co-

\footnotetext{
1 Fray Tomas Ruiz, fue el líder ideológico de dicha insurrección y antes había dirigido protestas contra el pago de impuestos a la corona española, fue el fundador de la Universidad Nacional en León y después de la insurrección de 1812, se traslado a Guatemala para llevar el movimiento insurreccional al corazón del poder colonial, pero fue delatado y apresado, permaneciendo bajo torturas hasta 1,919, falleciendo en el mismo año luego de haber sido liberado, sin lograr ver los cambios por los que ofrendó su vida.
} 


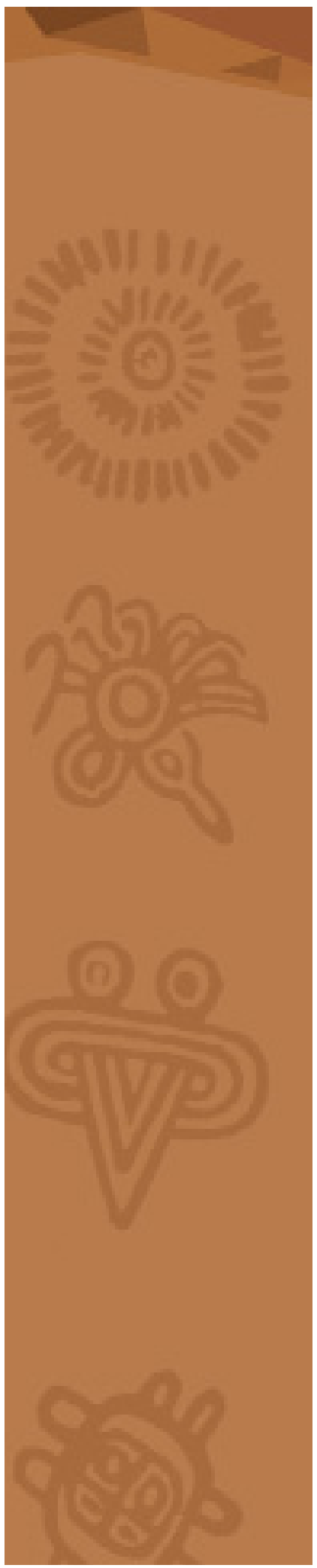

munidad Internacional, en cuanto a la adecuación del ordenamiento jurídico nacional a los instrumentos de derecho internacional ratificados por Nicaragua y en algunos aspectos se ha adelantado, dando mayores pautas, más allá de las dictadas en dichos instrumentos.

Adicionalmente se han venido transformando y creando políticas públicas orientadas a garantizar el cumplimiento de las disposiciones constitucionales y legales que se han aprobado. En el ámbito cultural, se han definido Políticas Culturales por parte del Poder Ejecutivo y por los Gobiernos Regionales de la Costa Caribe. El Poder Legislativo ha adoptado una Política de Interculturalidad que la establece como eje transversal en todo el proceso de formación de la ley y en el funcionamiento de sus diferentes instancias.

\section{Diversidad Cultural en Nicaragua}

En Nicaragua conviven actualmente diez culturas diferentes, reconocidas oficialmente, tales son: culturas originarias como la Miskita en la Región Autónoma de la Costa Caribe Norte (RACCN), al norte del Departamento de Jinotega y norte de la Región Autónoma de la Costa Caribe Sur (RACCS), Sumu-Mayangna en la misma zona, Rama en la RACCS. Los Chorotegas, ubicados en el norte, centro y oriente del país, Nahualt o Nahoas en la región del pacífico sur, Okanos o Sutiabas en la región occidental, León. Las culturas afrodescendientes como la Krioll o Creole en la Región Autónoma de la Costa Caribe Sur RACCS y parte de la Región Autónoma de la Costa Caribe Norte RACCN, Garífuna en la Región Autónoma de la Costa Caribe Sur RACCS y la cultura mestiza que el Estado ha asumido como oficial y que se mantenía como la única cultura reconocida hasta hace tres décadas.

Las culturas no tienen fronteras claras, por el contrario, siempre entran en contacto mediante procesos históricos. La existencia de esta diversidad cultural y la ausencia de mecanismos de convivencia entre las culturas ha sido un factor de conflicto que se ha manifestado a lo largo de toda la historia. Ante esta realidad, se requiere de una Política de Estado orientada al reconocimiento y garantía de los derechos culturales de los diferentes pueblos.

La interculturalidad como necesidad histórica para que los pueblos que cohabitan en un mismo territorio, puedan coexistir, está determinada por las relaciones de poder. A lo largo de la historia de Nicaragua, vamos a encontrar que las relaciones entre los diferentes pueblos, se han desarrollado en una lucha constante por el ejercicio del poder entre los pueblos en un estatus de subordinación cultural, económica, política y social y las clases dominantes que inicialmente fueron los peninsulares y posteriormente sus descendientes criollos.

Analizar las relaciones de poder permite abordar el problema objetivamente y a fondo; pues el problema de las relaciones entre los diferentes pueblos y culturas radica en las estructuras de poder y toma de decisiones, mientras éstas no cambien, no puede haber espacio para la interculturalidad. Si los pueblos indígenas y afrodescendientes no tienen participación en la vida política, económica y social del Estado, no se puede hablar de interculturalidad. 


\section{El estado actual de la interculturalidad en Nicaragua, reporta un avanzado posi- cionamiento a nivel jurídico y político, que tiene como coro- lario la Reforma Con- stitucional aprobada en febrero del 2014.}

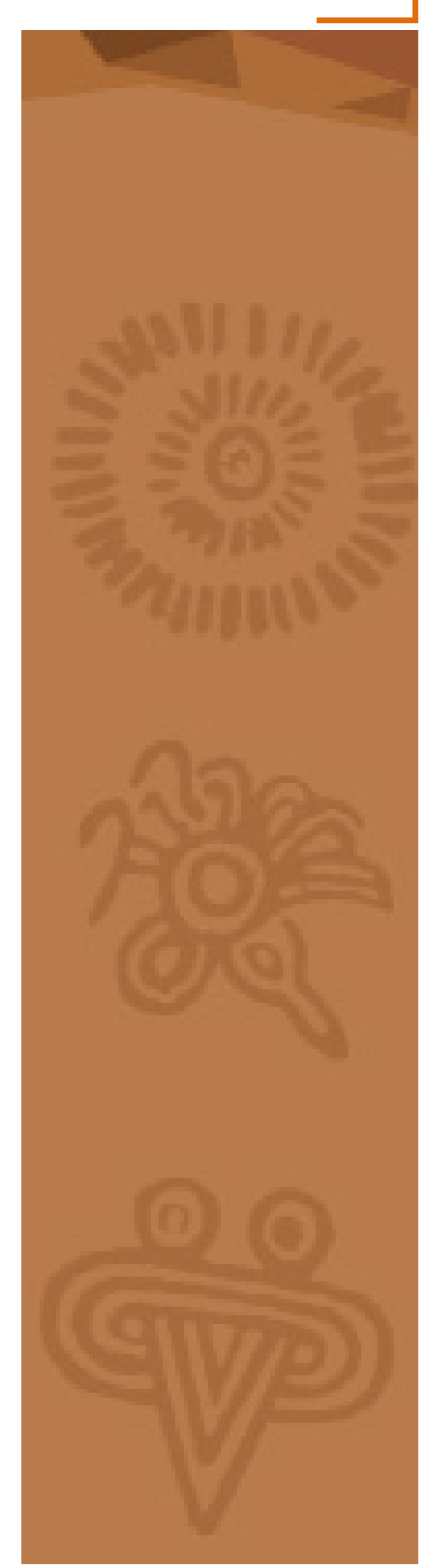

Es importante aclarar que la interculturalidad no se refiere tan solo a la interacción con los pueblos originarios y afrodescendientes, sino a cualquier otra cultura existente en el país. Con la salvedad que, para el caso de Nicaragua, son las culturas que interactúan junto a la cultura hispánica. Tampoco se limita a situaciones que ocurre a nivel geográfico sino más bien, en cada una de las situaciones en las que se presentan diferencias culturales.

El proceso de reconocimiento y afirmación de los derechos culturales de los diferentes pueblos originarios y afrodescendientes existentes en Nicaragua, lleva más de 39 años, desde que se publicó el Decreto No. 571, Ley Sobre Educación en Lenguas en la Costa Atlántica del 25 de noviembre de 1980, publicada en La Gaceta No. 279 de 3 de diciembre de 1980. Desde entonces el proceso ha venido avanzando consistentemente hasta llegar al nivel actual, que sitúa a Nicaragua como uno de los países más avanzados de América en ésta materia.

Sin embargo, el tema de la convivencia cultural sigue siendo un desafío que requiere de la acción comprometida de las diferentes entidades de la Comunidad Internacional en Nicaragua y de las instituciones del Estado; entre las cuales destaca el Poder Legislativo, mediante la aprobación de leyes que en diferentes materias han incluido la interculturalidad como eje transversal.

En tanto que la diversidad cultural trastoca todos los ámbitos de la vida de una sociedad, la interculturalidad debe penetrar todos los espacios de relación entre las diferentes culturas. El estado actual de la interculturalidad en Nicaragua, reporta un avanzado posicionamiento a nivel jurídico y político, que tiene como corolario la Reforma Constitucional aprobada en febrero del 2014; no obstante, estos avances legislativos, no se corresponden con la percepción y nivel de aceptación en la sociedad, que desde sus cimientos ideológicos sigue impregnada de la visión colonial de si misma, lo cual deviene a ser el reto más importante para todos los actores interesados en este tema: erradicar el colonialismo interno.

\section{Construcción de un Estado Multicultural}

Posterior a la independencia, se asumió la creación de Estados en las antiguas provincias coloniales, cuyas fronteras física y socialmente eran inciertas. Los pueblos o naciones existentes durante la Colonia, eran regidos básicamente de conformidad con su propia dinámica cultural y las fronteras terrestres de las provincias no significaban para ellos una barrera que impidiera su existencia y su dinámica social.

Después de la llamada independencia, las fronteras estatales, definidas ahora bajo el concepto de Soberanía, no permitirían el desarrollo de la convivencia integral de estas nacionalidades y muchas se vieron fragmentadas, al quedar enclaustradas en las nuevas fronteras artificialmente impuestas. Es el caso de los Miskitos en la frontera honduro-nicaragüense, los lencas-jicaques y Matagalpa con Honduras y el Salvador, los mayas entre Honduras y Guatemala, 


\section{El Estado Nación vino a destruir las ancestral- es formas de organ- ización socio-cultural de la sociedad nica- ragüense.}

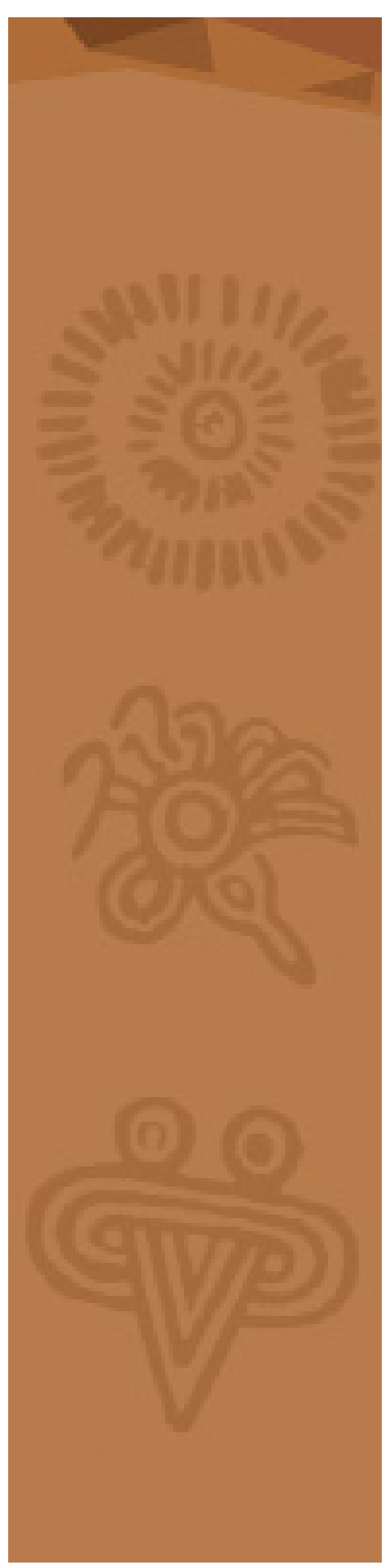

como también entre Guatemala - México y Guatemala -Belice, los Chorotegas entre Nicaragua y Costa Rica y entre Nicaragua y Honduras, o los Bribri entre Costa Rica y Panamá.

\section{El Modelo Estado Nación}

Establecido el nuevo Gobierno Republicano, cuando ya las autoridades reales habían sido relegadas de funciones, las élites criollas, copiando las estrategias de sus homólogas latinoamericanas, tuvieron que organizarse para asumir el poder en la ex provincia de Nicaragua. Aunque tardíamente, se organizaron para crear un sistema político, que respondiera a sus intereses económicos, sociales y culturales.

Durante las primeras cuatro décadas, los grupos dominantes no pudieron articularse para impulsar con efectividad su proyecto. Fue hasta que lograron resolver los conflictos internos con el fin de la Guerra Nacional, que se intensificó la campaña de colonización del centro y el norte del país.

En su estrategia de consolidar el dominio sobre las mayorías indígenas y afrodescendientes, impulsaron la política de despojo de tierras indígenas. Se promovió el ingreso de personas extranjeras, especialmente del norte de Europa, para que contribuyeran a "civilizar" a los nativos, implementando nuevos conocimientos y tecnologías, con lo cual podrían avanzar en el desarrollo económico del país. El eje motivador de esta campaña fue el cultivo del café, que a partir de 1,860 se impulsó en el centro y de 1,885 en el norte del país. El café, declarado actividad económica de interés supremo de la nación, hizo desaparecer las tierras comunales de Diriomo² (Dore, 2008).

Con la Revolución Liberal se inició una nueva etapa, en la cual, el ascenso de los mestizos y algunos criollos liberales, abrieron paso a un nuevo modelo de desarrollo para el país. Era una época nueva para muchos, pero la situación de los indígenas y afrodescendientes, seguiría siendo esencialmente igual, con una ligera diferencia, la implementación del trabajo asalariado que antes se realizaba, bajo condiciones semi feudales.

Se acogió el Modelo de Estado Nación, que ya había sido implementado en algunos países vecinos, basado en sistema Monoétnico, Monocultural y Monolingüe, destinado a fortalecer la hegemonía política de una nueva clase, que ascendía y prometía ser la base del nuevo poder: los mestizos adinerados.

El Estado Nación vino a destruir las ancestrales formas de organización socio-cultural de la sociedad nicaragüense. Es concebido como una asociación de individuos, que se unen libremente por contrato. La sociedad no es vista como una compleja red de grupos, de símbolos, asociaciones, culturas diversas que han ido desarrollándose a lo largo de la historia; sino como un grupo de indi-

2 Dore, Elisabeth. Mitos de Modernidad. IHNCA-UCA 2008. Pág. 128-143.

3 Villoro, Luis. Estado Plural, Pluralidad de Culturas. Facultad de Filosofía y Letras Universidad Nacional Autónoma de México. 1999. Pág. 25. 
Los indígenas fueron excluidos como ciudadanos y con ello se coartó la posibilidad de cualquier tipo de participación en la vida política del país

viduos que convienen en hacer suya una voluntad general. La expresión de la voluntad general es la ley, que rige a todos sin distinciones. Ante la ley todos los individuos se uniforman. Nadie tiene derecho a ser diferente. El nuevo Estado establece la homogeneidad en una sociedad heterogénea3 (Villoro, 1999).

La nación moderna no resultó de la asociación de grupos, estamentos, comunidades, naciones distintas, sino que fue producto de una decisión de individuos que comparten una sola cualidad: ser ciudadanos. Por supuesto que, en esa categoría, no cabrían los indígenas. ni los afrodescendientes.

Los indígenas fueron excluidos como ciudadanos y con ello se coartó la posibilidad de cualquier tipo de participación en la vida política del país. Los conceptos de ciudadanía fueron delineados bajo la visión dominante de que los indígenas eran como lo expresaron en la época de las sublevaciones de 1811, lo peor de la sociedad y había que tratarlos como pueblos conquistados.

Así el ejercicio del poder sería el privilegio de los nuevos colonos. Los parámetros y requisitos de ciudadanía definidos en la Constitución no permitían un lugar a los indígenas, sea porque carecían de una propiedad individual, sea por que no sabían leer y escribir o porque no tenían un oficio o profesión e incluso por no ser casados; condiciones que el sistema de organización social de la cultura indígena no podía llenar.

La constitución desde 1,826 establecía: “Art. 18 Son ciudadanos todos los nicaragüenses naturales o naturalizados que sean casados, o mayores de diezy ocho años, y que tengan una propiedad, o que ejerzan algún oficio o profesión de que subsistan, calificado todo en los términos que designa la Ley.” “Art. 22- Se suspenden los derechos de ciudadano: $\quad 3 .-$ Por la condición de sirviente doméstico cerca de la persona. " Esta misma disposición fue retomada en las siguientes constituciones durante todo el siglo. ${ }^{4}$

La Constitución liberal de 1893, la cual fue proclamada para restituir los derechos civiles, aunque introdujo una ligera variante, siempre excluyó a los indígenas. La Revolución Liberal, si bien eliminaba la discriminación por razones económicas, la mantenía por razones culturales, al establecer el requisito de saber leer y escribir para ser ciudadano, agregando otro elemento más de exclusión, como es la vagancia habitual.

Con ésta calificación fueron reprimidos los indígenas que se rehusaban a cumplir la ley de Trabajo Forzoso implementada desde 1,881. “Arto.20. Son ciudadanos todos los nicaragüenses mayores de diez y ocho años, y los mayores de diez y seis que sean casados ó sepan leer y escribir. Art. 22. Se suspenden los derechos de ciudadano: Inciso 2o. Por vagancia legalmente declarada: Luego para sellar la exclusión, en el artículo 25 se estableció: Sólo los ciudadanos mayores de 21 años que se hallen en ejercicio de sus derechos, son elegibles." ${ }^{5}$ Es decir, los indígenas y afrodescendientes, no podrían ni siquiera elegir, mucho menos ser electos.

4 Estas mismas disposiciones son recurrentes en las Constituciones de 1838 art. 18 y 22 inciso 5, de 1854 art. 12 y 14 inciso 5 , de 1858 Art. 8 y 10 inciso 3.

5 Constitución aprobada el 10 de diciembre de 1893. 
Los centros de difusión de la doctrina mestiza, pasaron de la iglesia a la escuela.
El concepto de ciudadano, era nuevo para los indígenas y afrodescendientes, que no concebían la individualidad, sino más bien se veían como sujeto colectivo frente al Estado. Pero con el nuevo orden, se vino a resquebrajar la identidad colectiva, los individuos, ya no pertenecerían al Pueblo Indígena, sino al Estado.

Todos los individuos, al menos los que llenaran los requisitos exigidos, sin importar su pertenencia a un pueblo, nación o cultura diferente, eran ahora miembros de una nueva entidad, que estaba por encima de sus formas de organización política ancestral. Así, dejaban de ser miembros de un pueblo y se convertían en ciudadanos del Estado.

Adicionalmente, se organiza el desmontaje de las estructuras culturales de las diversas naciones existentes en el país. Esta nueva idea de pueblo y nación, rompe con la nación original, concebida como una entidad histórica, unida por lazos culturales, sociales y territoriales. Por el contrario, crea un pueblo ficticio, de individuos abstractos, sin identidad, que reemplaza a los pueblos reales, una nación construida reemplaza a las naciones históricas.

Se crea una nación que ya no es la expresión de una cultura específica a la cual pertenecen los individuos, sino un espacio público que resulta de la suma de todos los individuos, sin cultura propia, que tendrán que adoptar la nueva cultura que se les imponga. El Estado es el garante de la construcción de esa nueva nación ${ }^{6}$ (Villoro, 1999).

El Estado Nación, debe borrar la multiplicidad de las comunidades sobre las que se impone y establecer sobre ellas un orden homogéneo. Está en contra de la división de culturas diferenciadas, etnias o nacionalidades, no admite ninguna clase fuera de los derechos específicos. De ahí que, al integrarse al Estado, el individuo debe hacer a un lado sus peculiares rasgos biológicos, étnicos, sociales o regionales, para convertirse en simple ciudadano igual a todos los demás. La función de ciudadano no hace diferencia de ningún tipo, lo despoja de su pertenencia a comunidades concretas para "en igualdad de condiciones" con todos los demás individuos, formular un nuevo "contrato social". Contrato según el cual, el individuo ha de ser extirpado de su comunidad de origen, para reintegrarlo a una nueva sociedad de leyes. ${ }^{7}$

El concepto de Estado Nación, pretendió justificar la implementación de políticas de homogeneización cultural, orientadas a englobar bajo una sola cultura a todas las nacionalidades y diversidad cultural existente, bajo la premisa del desarrollo y la modernización, que son la continuación de la civilización colonial. En el caso de Nicaragua no había cultura en singular sino culturas en plural, pero el Estado Nación, se enfocó en crear artificialmente una cultura que debía sintetizar toda esa diversidad, la llamada cultura nacional, la nicaraguanidad, lo cual significaba absorber y desaparecer la diversidad, la pluriculturalidad.

\footnotetext{
6 Villoro, Luis. Op.Cit.
}

7 Villoro, Luis. Op.Cit.

8 Raíces Indígenas de la lucha anticolonialista en Nicaragua de Jaime Wheelock Román y El mito de la Nicaragua Mestiza, de Jeffrey Gould, son lecturas obligadas para quienes quieran profundizar en el conocimiento de esta estrategia que durante un siglo le funcionó bien a los grupos hegemónicos. 


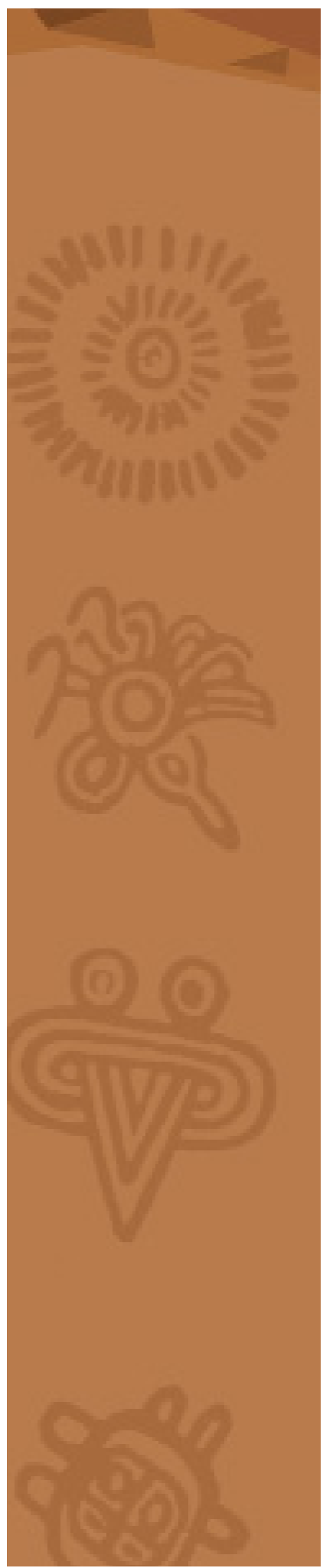

El mito de la Nicaragua mestiza, fue el fundamento ideológico de toda la política integracionista impulsada bajo el Modelo Estado Nación, como una estrategia de sometimiento cultural más efectiva que la del sistema colonial. Éste fue adoptado después del alzamiento de los indígenas Matagalpa y bajo este precepto ideológico se articularon todas las políticas públicas del Estado, en la educación, la salud, la cultura, la economía y la producción, así como todo el sistema de relaciones sociales. ${ }^{8}$

Mediante el Mito del Mestizaje, se ha llegado a convencer a diferentes sectores de la sociedad, incluyendo muchos indígenas y afrodescendientes, de que son otro ser diferente al que llevan dentro. El colonialismo en la época republicana adoptó la educación como el medio predilecto de adoctrinamiento, que en la etapa colonial anterior se había asignado a la religión. Por tanto, los centros de difusión de la doctrina mestiza, pasaron de la iglesia a la escuela.

En lo político, se formó una sociedad, bajo una visión colonizada, la ciudadanía comenzó a padecer el "síndrome del colonizado", que enseñó a no pensar con mentalidad propia, sino con mentalidad ajena, a actuar no con voluntad propia, sino con voluntad ajena y a obedecer no a los intereses propios, sino a intereses ajenos y por supuesto a seguir a lideres ajenos y no a los propios. Es decir, a apreciar lo ajeno y menospreciar lo propio.

Por su naturaleza el Modelo de Estado Nación, no se ajusta a una sociedad étnica y culturalmente diversa. De ahí que siempre estuvo en una contradicción intrínseca, entre el sistema político y la realidad socio-cultural. El Estado Nación, caracterizado por una política integracionista e indigenista en su etapa más progresista, no podía generar espacios para el pleno desarrollo de los pueblos originarios y afrodescendientes.

Por diferentes medios y mecanismos de influencia, utilizando las ventajas del poder, el sistema impuso la cultura dominante, la que ha calado profundamente en la sociedad en general y en las culturas en particular. Adicionalmente, la imposición cultural ha afectado los niveles de vida de la población de los pueblos originarios y afrodescendientes, a los cuales les ha disminuido sus capacidades colectivas para el autodesarrollo o el bien vivir como se le llama desde adentro.

En la salud, la medicina tradicional que le garantiza el acceso a la salud de manera estable y sostenible y el conocimiento de las comunidades, se ha venido perdiendo. En lo económico, la imposición de los agroquímicos ha contaminado y desgastado los suelos, ha elevado los costos de producción, además ha generado nuevas plagas y enfermedades de los cultivos que lo hacen cada día más dependiente. Ha convertido la tierra en una mercancía mas, lo que ha estimulado la toma de tierras en la Costa Caribe, por colonos provenientes de las regiones central y pacífica del país,

9 Entrevista con líderes del Gobierno Territorial Rama Kriol, entrevistados el 22 de octubre 2012. 
De un Estado que integra y absorbe, se ha convertido en un Estado que incluye y se adapta.

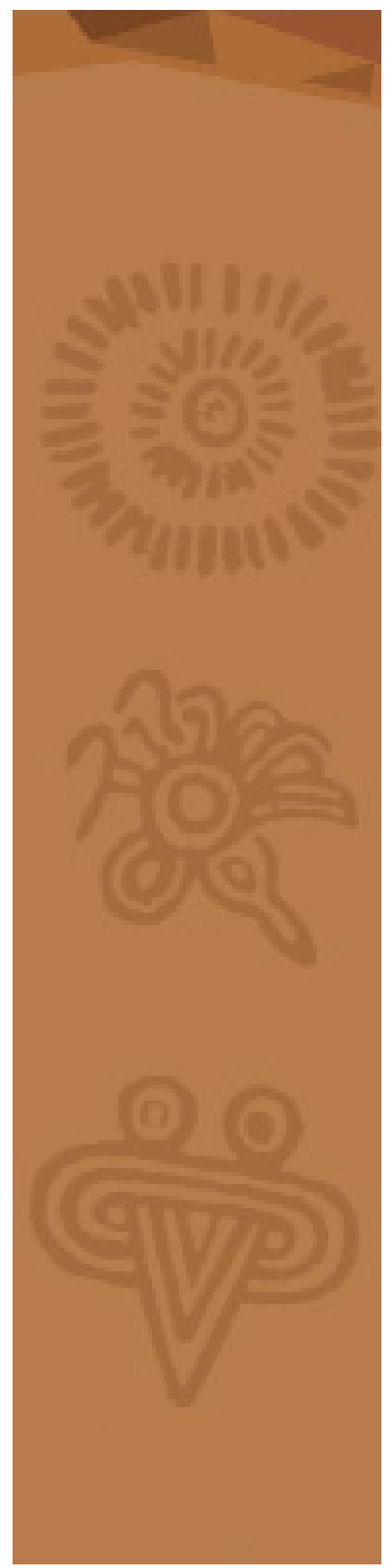

quienes van destruyendo los bosques y la llamada frontera agrícola está desapareciendo, porque ya están llegando a la costa del mar Caribe.

Así no solo se están destruyendo los recursos vitales de los pueblos indígenas y afrodescendientes, sino también su cultura y sus formas de vida'. Todo esto vuelve más vulnerable a la población ante las enfermedades y ante la crisis económica.

Lo antes dicho, implica que se debe invertir para levantar la posición de las culturas más débiles y ubicarlas en condiciones de igualdad con las culturas más fuertes, para que pueda funcionar una relación equitativa entre las diferentes culturas, pues ésta es la esencia de la interculturalidad. Sin embargo, los pueblos indígenas y afro descendientes, deben asumir la revitalización cultural, con la beligerancia que merece, pues de otra manera no se podrán preservar las culturas. Ahora más que nunca la revitalización de la cultura autóctona, se vuelve un asunto vital y una premisa para cualquier estrategia de desarrollo.

El Modelo Estado Monoétnico, fue concebido desde la independencia, sobre una realidad multiétnica y pluricultural; este es un mal congénito que el Estado nicaragüense padece desde su nacimiento. La enfermedad empeoró con el Modelo Estado-Nación, que profundizó la contradicción entre el sistema político y la realidad sociocultural y funcionó por la fuerza del poder hasta 1,979, en que se rompe la estructura política y se inicia la creación de un Estado representativo.

\section{El Nuevo Estado Multicultural}

El Estado de Nicaragua, especialmente a partir de los años 80 inicia un sostenido proceso de reconocimiento de los derechos fundamentales de los Pueblos Indígenas $\mathrm{y}$ afrodescendientes, el cual ha permitido realizar profundas transformaciones en el ordenamiento jurídico nacional, para transitar del Estado Monocultural y Monoétnico al Estado Multicultural y Plurinacional.

Como se ha referido en apartados anteriores, estos cambios en el sistema jurídico y político del Estado nicaragüense, son producto de las luchas protagónicas de los pueblos originarios y afrodescendientes, en todos los procesos políticos que han sucedido en el país desde hace siglos. Sin embargo, cabe destacar que los mayores avances se han producido en las últimas tres décadas.

Después de la guerra de los años 80 , en condiciones de paz, se ha producido un diálogo intercultural basado en las garantías establecidas en la Constitución de 1,987. El diálogo intercultural ha permitido abrir espacios a la participación política de los Pueblos Originarios y Afrodescendientes, mediante lo cual han escalado a posiciones muy importantes, en las estructuras de poder del Estado.

Como producto de este proceso emergente de las culturas y naciones anteriormente excluidas, en Nicaragua se han adoptado los instrumentos internacionales de dere- 
chos de los pueblos y se ha producido una amplia legislación ordinaria, especialmente referida a dichos pueblos, pero además se ha tenido presente sus particularidades y el reconocimiento de sus derechos, en la mayoría de las leyes aprobadas en las últimas tres legislaturas de la Asamblea Nacional.

El cambio fundamental del Estado de Nicaragua, en su más moderna reforma aprobada en febrero de 2014, es que ha optado por integrarse de manera dialéctica a esta realidad diversa culturalmente. Así ha modificado su estructura y esencia. En vez de convertir a las culturas de las diversas nacionalidades existentes en una sola cultura, como lo pretendió el modelo Estado Nación, se ha convertido en un Estado Pluricultural, en el cual las diferentes culturas tienen su espacio asegurado dentro del mismo Estado. De un Estado que integra y absorbe, se ha convertido en un Estado que incluye y se adapta.

\section{Conclusiones y Recomendaciones}

El proceso de interacción cultural en el Estado de Nicaragua, ha transitado por varias etapas. Primera etapa: Hispanidad Criolla, de 1,821 a 1893, establecimiento del proyecto colonizador propio y la imposición de la cultura hispánica, para las regiones del Pacífico, Centro y Norte. Para la Costa Caribe es el Protectorado Inglés. Segunda etapa: Estado Nación, de 1,893 a 1980, homogenización cultural bajo el ideario del mestizaje para crear una cultura nacional artificial. Tercera etapa 1,980 a 2,015 Creación del Estado Pluricultural y establecimiento de la interculturalidad como política de Estado.

En el ámbito jurídico, la interculturalidad ha sido adoptada como eje transversal del proceso legislativo, mediante el reconocimiento de los derechos colectivos fundamentales de los Pueblos Originarios y Afrodescendientes, implementando su enfoque en la legislación nacional.

En Nicaragua, se puede concluir que el Ordenamiento Jurídico Nacional ha sido adecuado al ordenamiento Jurídico Internacional, en materia de Derechos de los Pueblos Originarios y Afrodescendientes, con la incorporación de los instrumentos jurídicos del Derecho Internacional suscritos y ratificados por Nicaragua. En algunos aspectos, la legislación nacional supera la normativa internacional, como el caso del reconocimiento de los Pueblos Originarios y Afrodescendientes como entidades de ejercicio de soberanía, así como la equidad incondicional de género en la gestión pública.

En el ámbito político, el país se ubica en una muy alta posición, en el reconocimiento y ejercicio de la ciudadanía intercultural, la formulación de políticas públicas interculturales, la equidad incondicional de género en el ejercicio de la función pública, la incorporación de los Pueblos Originarios y Afrodescendientes como sujetos activos y protagonistas de los programas de desarrollo social y económico en sus territorios. 


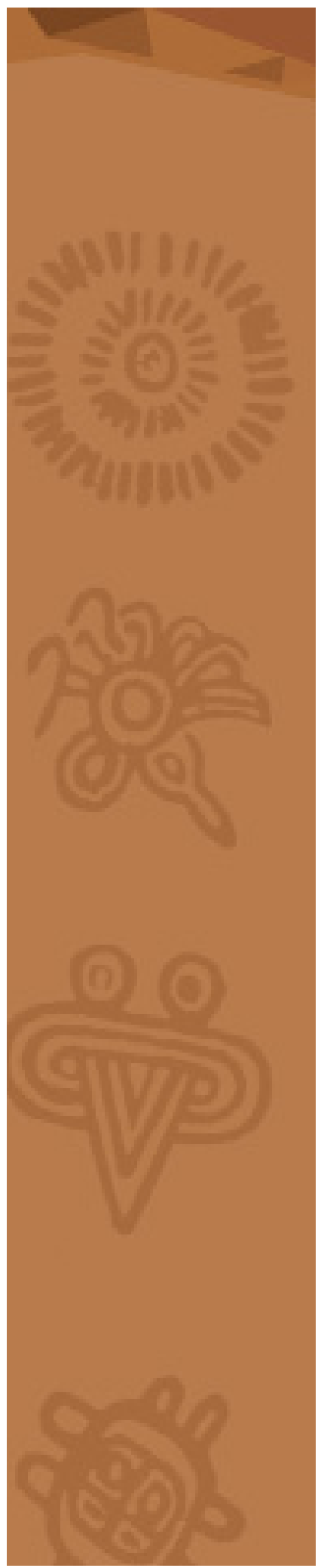

No obstante, los grandes avances alcanzados en el ámbito jurídico y político por el Estado, la visión de la sociedad nicaragüense adolece de los rezagos de la mentalidad colonial formada durante siglos. Ésta es la causa fundamental de la mayoría de los conflictos, que generan tensión a la Costa Caribe y otros territorios del pacífico, centro y norte del país.

\section{Recomendaciones}

Promover en la sociedad nicaragüense una visión intercultural, que fomente el respeto a la diversidad cultural. En este sentido se recomienda promover con prioridad la revitalización y afirmación de las culturas más afectadas, para fortalecer sus capacidades de dialogo e interacción con las demás culturas. Esto permitirá mejorar el comportamiento y la actitud de la población, para garantizar la convivencia y la gobernabilidad intercultural en el país.

Articular esfuerzos entre las diferentes instituciones del Estado y los Gobiernos Territoriales de los Pueblos Originarios y Afrodescendientes, en la divulgación y educación intercultural, para desarrollar la conciencia de identidad cultural en la población.

Incluir la interculturalidad como eje transversal en la investigación social, tanto en los temas referidos a las políticas públicas, como a los que abordan las relaciones sociales, a fin de valorar los avances alcanzados en las instituciones públicas y los mecanismos para fortalecer su aplicación e interacción con la sociedad.

Divulgación entre los diferentes sectores de la sociedad, los cambios adoptados en el Estado, a fin de promover el cambio actitud a partir de la nueva realidad política.

\section{Bibliografía}

Acosta Albergo. Interculturalidad y globalización. Santiago 1999.

Alavés Ruiz, Aleda. Interculturalidad: El caso de México. Ediciones Mesa Directiva. Cámara de Diputados. Congreso de México 2014.

Arellano Jorge Eduardo. La Nicaragua indígena que empezó en el Sur. Nuestro tronco chibcha y lengua rama en extinción. Artículo publicado en El Nuevo Diario. Edición del 15 de febrero 2009.

Arellano, Jorge Eduardo. La aristocracia criolla de Bluefields hace 115 años. Artículo publicado en El Nuevo Diario, edición del 20 de mayo 2009.

Asamblea Nacional. Decreto Legislativo Ley 3584. Reglamento de la Ley de Autonomía de la Costa Atlántica de Nicaragua. Publicado en la Gaceta Diario Oficial Número 186 del 2 de octubre del año dos mil tres. 
Bastos, Santiago. Análisis conceptual de la diversidad étnico cultural en Guatemala. En Informe de Derechos Humanos 2005 del PNUD en Guatemala.

Buenrostro Alba, Manuel. Pueblos Indígenas, Multiculturalismo e Interculturalidad.

Casaus Arzu, Marta Elena. La Metamorfosis del Racismo en Guatemala. Guatemala 2002.

Corona de la Peña Liza Claudia. Ciudadanía y Multietnicidad el caso de Nicaragua caracterización de la participación Política en territorios Indígenas de la Costa Caribe de Nicaragua. FLACSO México, D.F Julio 2006.

Díaz Raúl y Alonso Graciela. Integración e interculturalidad en épocas de globalización. Universidad Nacional de Camahue Neuquen. Septiembre 1998.

Dore, Elisabeth. Mitos de Modernidad. IHNCA-UCA. Managua.2008.

Fonseca Amador, Carlos, Obras. Tomo II. Viva Sandino. Centro de Publicaciones Silvio Mayorga. Managua 1980.

Gould, Jeffrey L. El mito de la Nicaragua Mestiza. La resistencia indígena 1,880-1,890. Instituto de Historia de Nicaragua. Editorial de la Universidad de Costa Rica. Primera Edición. 1997.

Historia de Bluefields. Alcaldía Municipal de Bluefields. Documento Oficial de Ficha Municipal.

Informe de la Conferencia Mundial contra el Racismo, la Discriminación Racial, la Xenofobia y las Formas Conexas de Intolerancia. Durban, 31 de agosto a 8 de septiembre de 2001

Instituto Nicaragüense de Cultura (INC) Políticas Culturales Del GRUN. Managua 2007.

Instituto Nicaragüense de Cultura (INC). Situación del Patrimonio Cultural.

Instituto Nicaragüense de Estadísticas y Censos (INEC). VIII Censo de Población y Vivienda 2005. Cifras Oficiales.

Iturralde, Diego A. La gestión de la multiculturalidad y la multietnicidad en América Latina. UNESCO 1995.

Kinloch Tijerino, Frances. Editora. Nicaragua en busca de su identidad. Instituto de Historia de Nicaragua. UCA. PNUD. Managua 1995.

Kymlika Will, Ciudadanía Multicultural. Flacso 2004.

José de Jesús López Monroy, José de Jesús. en Notas para el estudio del Derecho Indiano. Pg.81. 


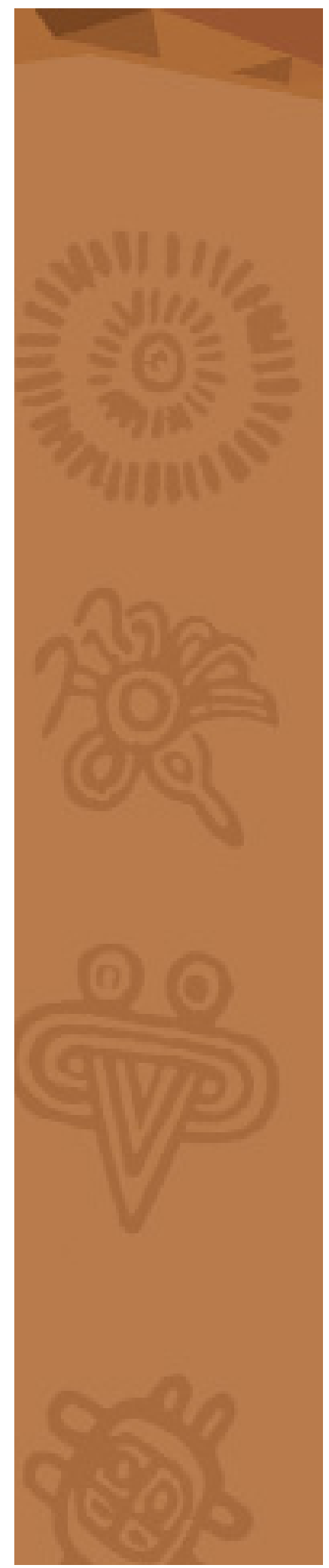

McLean Herrera, Guillermo, Interculturalidad Autonomía y Ciudadanía Intercultural en la Costa Caribe Nicaragüense. 11 de octubre 2012. Conferencia.

Mairena Ruiz, Rigoberto. Construyendo la ciudadanía Multicultural. Ensayo. Inédito. Managua 2,010.

Mairena Ruiz, Rigoberto. La propiedad Comunitaria en Nicaragua. Historia, evolución y situación actual. Publicación Segunda Jornada Centroamericana Tierra y Recursos Naturales. San Salvador 1999.

Mairena Ruiz, Rigoberto. La formación del Estado y la cuestión étnica en Nicaragua durante el siglo XIX. Universidad Nacional Autónoma de México-Universidad de San Carlos de Guatemala. Guatemala 2007.

Mairena Ruiz, Rigoberto. Informe sobre el Cumplimiento de la Convención sobre Eliminación de Todas las Formas de Discriminación Racial por parte del Estado de Nicaragua. Ginebra noviembre 2007.

Mairena Ruiz, Rigoberto. Desafíos para avanzar en la construcción de un Estado Multicultural en Nicaragua. - Exposición en Foro Nacional de Pueblos Indígenas. Asamblea Nacional. 2 de abril 2009.

Mairena Ruiz, Rigoberto. Participación Política Indígena en Nicaragua. Ensayo inédito. Nicaragua 2006.

-Mairena Ruiz, Rigoberto. Ombudsman y acceso a la Justicia de los Pueblos Indígenas, el caso de Nicaragua. Instituto Interamericano de Derechos Humanos. San José Costa Rica. 2004.-

Montoya Rojas, Rodrigo. Cultura y culturas: desde la colonialidad del poder y desde los pueblos indígenas. Universidad Ricardo Palma y Universidad Nacional Mayor de San Marcos. Lima, septiembre de 2011.

Ordoñez Cifuentes, José Emilio Rolando, La Constitución del Estado Nación Guatemalteco: El Ascenso etnocéntrico ladino y la configuración del colonialismo interno. Universidad Nacional Autónoma de México. México 1996.

PNUD. Revitalización Cultural, Desarrollo Productivo Creativo en la Costa Caribe de Nicaragua. Octubre 2008. En www.undp.org

Puga Cristina. Peschard Jacqueline y Castro Teresita. Sociedad y Cultura. Editorial Alhambra. México. 1995.

Rachel Sieder, "Del indigenismo institucional integracionista a la gestión pluralista de las políticas públicas". Instituto para estudios de las Américas, Universidad de Londres.

Ramirez Mercado, Sergio. Tambor Olvidado. San José Costa Rica 2007. 
Revista Temas Nicaragüenses. Edición Número 28 Agosto 2010

Rizo Zeledón, Mario. Identidad y derecho: Los Títulos Reales del Pueblo de Sutiaba. Instituto de Historia de Nicaragua y Centroamérica. IHNCA-UCA.1999.

Rodríguez Gil, Adolfo. Globalización e interculturalidad. Revista En Grupo Numero1. Año 1998.

Romero Vargas Germán - Historia de la Costa Atlántica.- CIDCA -1996.

Téllez, Dora María. Muera la Gobierna. Colonización en Matagalpa y Jinotega 1,820-1890. Universidad de las Regiones Autónomas de la Costa Caribe de Nicaragua. URACCAN 1999.

Villoro Luis. Estado Plural, pluaralidad de Culturas. Facultad de Filosofía y Letras, Universidad Autónoma de México.PAIDOS México,1999.

Wheelock Román, Jaime. Raíces Indígenas de la Lucha Anticolonialista en Nicaragua. Editorial Nueva Nicaragua. Segunda Edición en Nicaragua 1995.

Zelaya Goodman, Chester, Nicaragua en sus primeros años de vida independiente (1821-1825 ), en Revista Conservadora Número 54.

\section{Rigoberto Mairena Ruiz}

Abogado y Notario Público, estudio Ciencias Sociales y Derecho en la Universidad Nacional Autónoma de León. Con estudios especializados en Derecho Internacional Público, Derecho Empresarial, Derechos Humanos y Maestría en Derecho Indígena y Etnodesarrollo. Ha trabajado durante veinticinco años, con los Pueblos Indígenas del Pacífico Centro y Norte de Nicaragua. Su experiencia trasciende a lo puramente jurídico y al perfil de un abogado, pues ha incursionado en los campos de la docencia, la investigación histórica, la educación popular y la economía, para poder tratar la problemática de los Pueblos Indígenas que requiere un abordaje multidisciplinario.

En el campo de la administración de justicia, ha desarrollado una vasta experiencia como litigante, llevando los casos más emblemáticos, en los cuales se han ventilado ante las instancias judiciales, los derechos fundamentales de los Pueblos Indígenas. Ha sido el Asesor Jurídico principal de los Pueblos Indígenas en las regiones del Pacífico, Centro y Norte. Consultor de diferentes organismos sociales y de derechos humanos, vinculados a los Pueblos Indígenas en Nicaragua y del Instituto Interamericano de Derechos Humanos, Ha sido docente en la Universidad Nacional Autónoma de Nicaragua y ha impartido cursos especializados en Derecho Indígena a funcionarios judiciales, realizando además consultorías sobre interculturalidad con el Consejo Regional Autónomo del Caribe Sur y la Asamblea Nacional de la República de Nicaragua, así como también con Gobiernos Municipales. 